\title{
How we assess the perioperative anxiety of surgical patients with pulmonary nodules: the revision of state-trait anxiety inventory
}

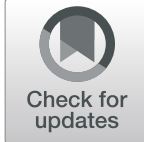

Zhenyu Zhou', Ying Wang ${ }^{2}$, Yuequn Niu', Zhehao He${ }^{1}$, Manli Huang ${ }^{3}$, Yuqiong Zhou², Wang Lv ${ }^{1}$ and Jian Hu ${ }^{1 *}$ (D)

\begin{abstract}
Purpose: The aim of the study was to develop a short form of State-Trait Anxiety Inventory (STAI) and calculate the norms for the assessment of anxiety in surgical patients in mainland China.

Methods: Patients who were scheduled to carry out pulmonary surgery in our department were included. The sinicized 40-item STAI Form-Y was used to assess the anxiety on the surgery eve. Then the coefficient of variation, coefficient of correlation, stepwise regression analysis, principal component analysis, and structural equation model were successively to filter the items. The reliability and validity of the revised STAI was estimated and the norms were computed.

Results: 445 intact replies were collected. A 13-item STAI with 6 items in state subscale and 7 items in trait subscale produced similar scores with the full version of STAI. The Cronbach alpha coefficients for the state and trait subscales were 0.924 and 0.936 , respectively. The determinant coefficients were 0.781 and 0.822 , respectively. Moreover, the norms of both state subscale and trait subscale are provided according to the age and gender.

Conclusions: The revised short form of STAI has good reliability and validity. It is likely to be more acceptable by reducing the fatigue effects, and is suitable for follow-up study on the assessment and intervention of perioperative anxiety of surgical patients with pulmonary nodules.
\end{abstract}

Keywords: State-trait anxiety inventory, Surgical patients, Perioperative anxiety, Structural equation model

\section{Introduction}

Lung cancer is still the most widespread and important malignant tumor at present, since it attributes over one eighth to the morbidity and nearly one quarter to the mortality in all malignant tumors [1]. Surgery is still the most effective treatment for patients with early-stage lung cancer [2-6]. At the beginning of twenty-first century, the concept of enhanced recovery after surgery (ERAS) emphasizes the integrated application of various methods to

\footnotetext{
* Correspondence: dr_hujian@zju.edu.cn

'Department of Thoracic Surgery, the First Affiliated Hospital, School of Medicine, Zhejiang University, Hangzhou 310003, China

Full list of author information is available at the end of the article
}

enhance perioperative management and promote postoperative recovery of patients as well, including pain relief, minimally invasive operation, and so on [7-11]. The assessment and intervention of perioperative anxiety should also be a part, and it is getting more and more attention [12-16].

Our department intends to conduct a registry study to assess and intervene perioperative anxiety in patients undergoing pulmonary surgery. To this end, we asked the mental health specialists to help us develop a comprehensive preoperative relaxation training process including progressive muscle relaxation training and breathing relaxation training $[2,14,17-19]$. At the same time, by consulting the literature, we

(c) The Author(s). 2020 Open Access This article is licensed under a Creative Commons Attribution 4.0 International License, which permits use, sharing, adaptation, distribution and reproduction in any medium or format, as long as you give appropriate credit to the original author(s) and the source, provide a link to the Creative Commons licence, and indicate if changes were made. The images or other third party material in this article are included in the article's Creative Commons licence, unless indicated otherwise in a credit line to the material. If material is not included in the article's Creative Commons licence and your intended use is not permitted by statutory regulation or exceeds the permitted use, you will need to obtain permission directly from the copyright holder. To view a copy of this licence, visit http://creativecommons.org/licenses/by/4.0/ The Creative Commons Public Domain Dedication waiver (http://creativecommons.org/publicdomain/zero/1.0/) applies to the data made available in this article, unless otherwise stated in a credit line to the data. 
selected the commonly used State-Trait Anxiety Inventory (STAI) as an indicator to assess perioperative anxiety.

Form Y, the most popular version of STAI, is a self-report, 40-item psychological test for adults, and it is divided into a State Anxiety Inventory (From Q01 to Q20) and a Trait Anxiety Inventory (From Q21 to Q40). Each item is rated on a 4-point Likert scale [20]. The state anxiety, which is an immediate and unstable emotional state, is assessed by the rating of his or her temporary feelings at the particular moment. And the trait anxiety, which is a relatively stable and enduring personality characteristic, is assessed by the rating of his or her general feelings across time [21]. The inventory has been reported to be suitable for use in clinical settings to assess the anxiety levels of unwell and healthy participants $[14,22-24]$. And it has also been translated to various languages including Chinese.

However, in the earlier small sample survey, we found that patients of different ages and different genders showed grate difference in preoperative anxiety. And STAI, as a 40-item inventory, was reported to be too complicated by several participants, similar as previous studies [23]. Thus, we conducted this pilot study to identify the population to participate the following study and to develop a revised version of STAI for use in the following study [25]. There are two main objectives in this study:

(i) to illustrate the gender and age group who have higher level of preoperative anxiety;

(ii) to revise the STAI Form-Y with less items to assess the preoperative anxiety of surgical patients with pulmonary nodules equally effectively.

\section{Materials and methods Patients selection}

From Aug 1st, 2018 to Jul. 31st, 2019, we filter the patients who were scheduled to carry out pulmonary surgery due to the suspected or confirmed lung cancer in our department.

The inclusion criteria were: No less than 18 years old (the standard for adults in mainland China); the patient's ability to directly communicate with medical staffs; the patient's informed consent (with no objection of family members); no history of pulmonary surgery.

The exclusion criteria were: Less than 18 years old (minors); planning to carry out other operations besides pulmonary surgery; no direct or smooth communication between the patient and medical staffs; refused by the patient or family members; involved in previous related researches; involved in other studies during this hospital stay; withdrawn at any time; other situations in which the patient is considered unable to complete the study.

\section{Materials}

We selected the State-Trait Anxiety Inventory (STAI) Form-Y to measure the anxiety of the patients. The inventory has respective norms for state anxiety and trait anxiety in different gender and age groups. A score higher than the norm is considered to be positive. We have published the online version of the inventory according to the Chinese version, which can be easily assessed by scanning the QR code or clicking the link using a smartphone Appendix 1.

\section{Procedure}

The research team consists of thoracic surgeons, mental health specialists, and operation room nurses. All members of the team are not the medical staffs directly responsible for the patients during the treatment. Firstly, surgeons collected information about the patients to be admitted for pulmonary surgery. Secondly, nurses contacted the patients in advance and sought their informed consent. On the surgery eve, when preoperative conversation and preparation were completed, our nurses would present the $\mathrm{QR}$ code or link to the patients and ask for their own answers. If the patient has reading or literacy difficulties, the staff would read out the contents of the inventory without inclination, and then the patient could answer by himself.

\section{Statistical analysis}

The significance level of all statistical analysis was set at $p<0.05$. Firstly, identify the excluded and reserved items. In IBM SPSS Statistics 25.0 (IBM, Armonk, New York, USA), the coefficient of variation (CV) was used to exclude the items whose $\mathrm{CV}$ was less than 0.250. The correlation coefficient (CC) method was used to exclude the items whose Spearman's rank correlation coefficient (R) with the subscale was less than 0.60 . The stepwise regression analysis was used to exclude the items which were not included in the regression analysis model. The principal component analysis (PCA) was used to excluded the items whose factor loadings were less than 0.500 on each factor or were close on two or more factors in the largest variance rotation model. In IBM SPSS Amos 26.0 (IBM, Armonk, New York, USA), the confirmatory factor analysis was carried out to establish a structural equation model and then modify the model in order to get the reserved items of the revised STAI.

Structural equation model (SEM) is a confirmatory factor analysis, which is used to explore the correlation between independent variable (item score) and 


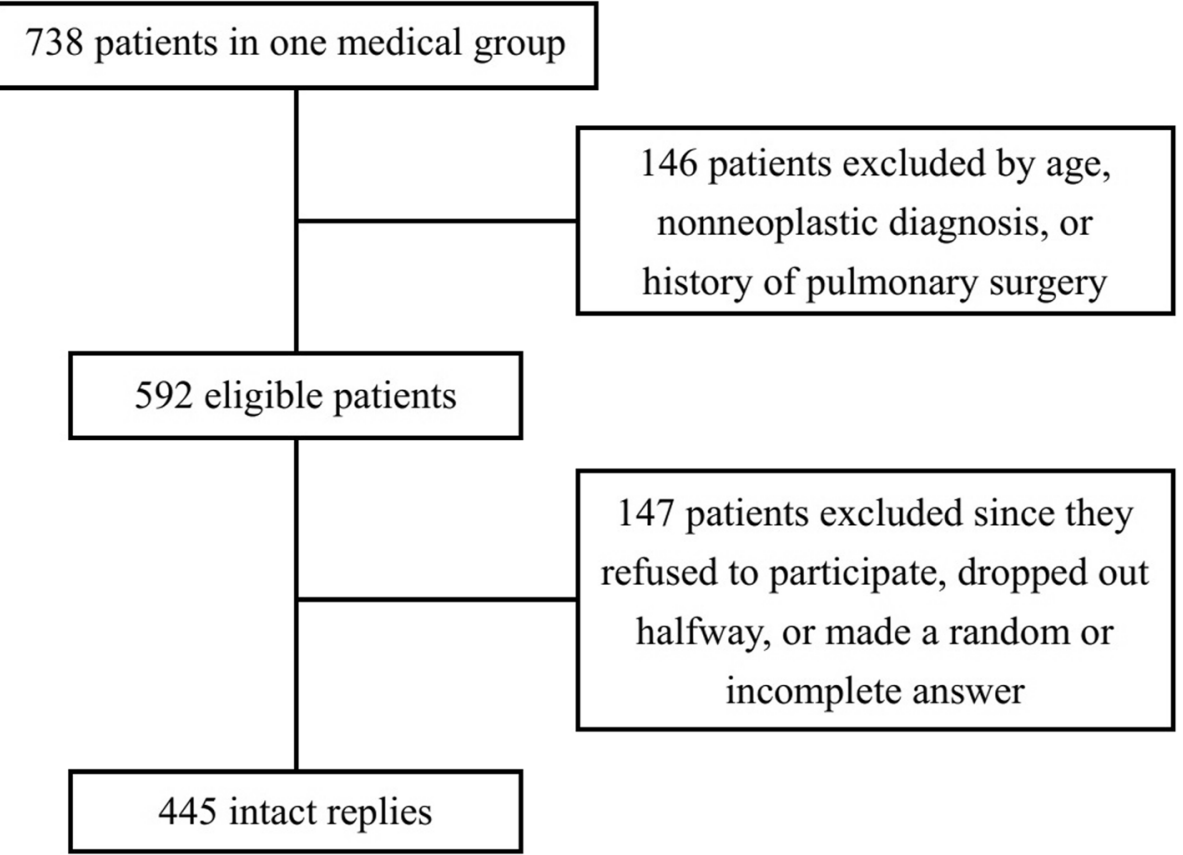

Fig. 1 The Flow Chart of Patients Selection

dependent variable (subscale score). Chi square $\left(x^{2}\right)$, Goodness-of-Fit Index (GFI) and Root Mean Square Error of Approximation (RMSEA) are important fitting indexes of SEM. The larger the GFI is, and the smaller the $X^{2}$ and RMSEA are, the better the fitting degree of SEM is. Item filtering started from the item whose regression weight with the subscale score was the smallest. If the SEM fitting is better after the deleting of an item, the item was confirmed to be deleted. While if the SEM fitted worse after the deleting, the item would be retained. It would be repeated until the best SEM fitting was achieved. At this point, the items which were still kept in the SEM were the ones we would keep for the revised STAI.

Secondly, estimate the reliability and validity of the revised STAI. Cronbach $\alpha$ was used to evaluate the internal consistency. The decision coefficient, $r^{2}$, of the scores of revised STAI and the original STAI Form-Y was calculated using correlation analysis. And the Youden index of revised STAI, which is 1.000 less than the sum of sensitivity and specificity, was calculated. A Youden index close to 0 indicates that the accuracy of the inventory is poor, while a Youden index close to 1 indicates that the accuracy is perfect.

Thirdly, compute the norm of the revised STAI through the linear regression analysis with the original norm.

At last, determine the appropriate patient groups for the following study according to the positive rate of perioperative anxiety in different age and gender groups.

\section{Results}

\section{Demography}

We distributed the inventory to 592 eligible patients, and then collected 445 intact replies. The response rate was $75.2 \%$ (Fig. 1). The demographic characteristics of the participants are shown in Table 1. All the patients would undergo a radical resection of the suspected or confirmed lung cancer.

\section{The revised STAI}

No items were excluded due to the $\mathrm{CV}$, and no items were excluded by the regression analysis model. In the CC statistics, 4 items (Q01, Q07, Q12 and Q14) in State subscale (S-AI) and 10 items (Q24, Q25, Q28, Q29, Q31, Q32, Q35, Q37, Q38 and Q40) in Trait subscale (T-AI) were excluded due to the low

Table 1 The Demographic Characteristics of Participants

\begin{tabular}{lll}
\hline & No. & $\%$ \\
\hline Gender & & \\
Male & 226 & 50.8 \\
Female & 219 & 49.2 \\
Age Group & & \\
18 and below & 0 & - \\
$19-39$ & 41 & 9.2 \\
$40-49$ & 76 & 17.1 \\
$50-60$ & 148 & 33.3 \\
61 and above & 180 & 40.4 \\
\hline
\end{tabular}




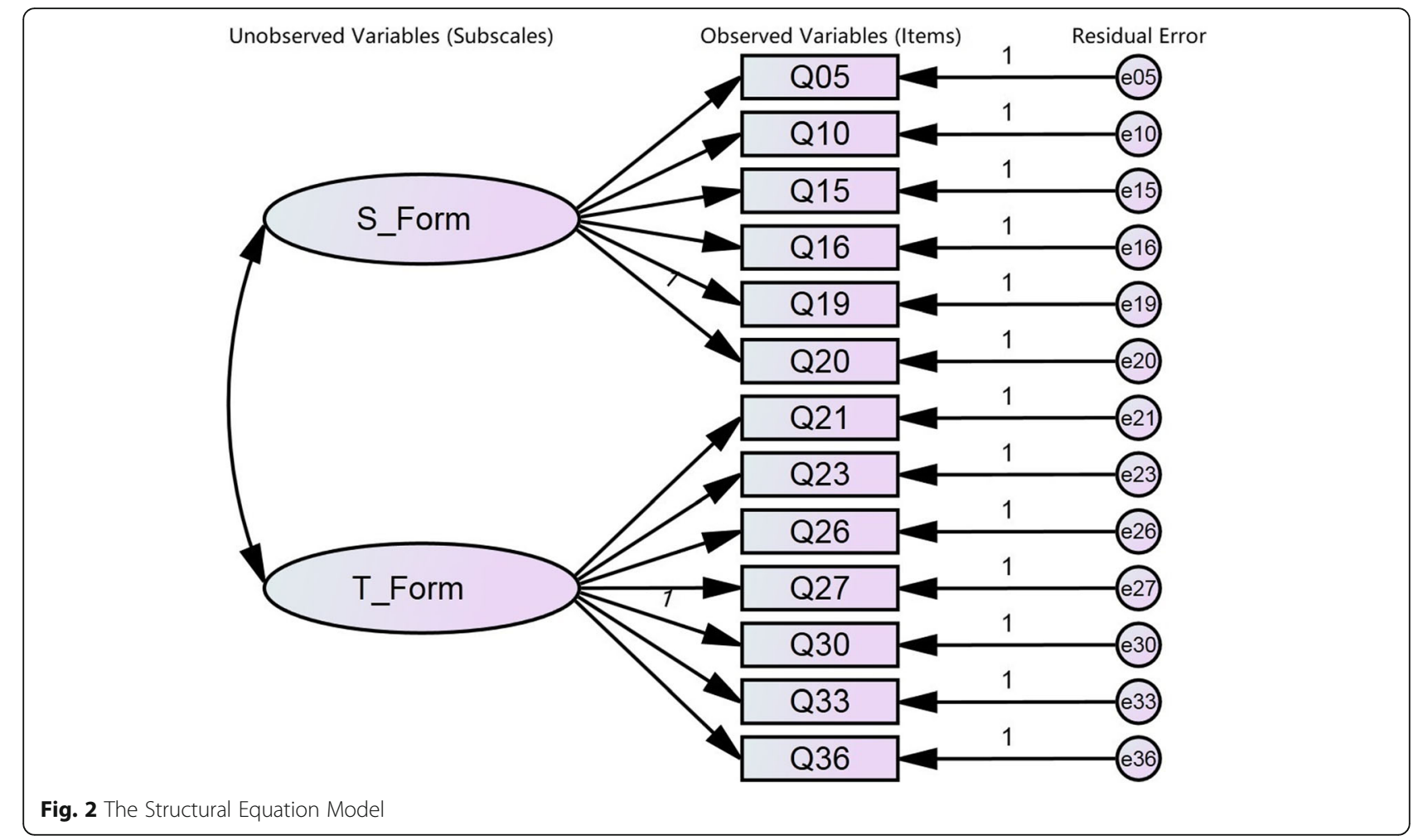

value of R. In PCA statistics, the KMOs of S-AI and T-AI were 0.942 and 0.943 . That means the set of data is available for PCA. Then no more items were excluded.

Input the left 16 items of S-AI and 10 items of T-AI into the structural equation model. After calculation, a revised 13-item STAI was obtained with a 6-item S-AI (Q05, Q10, Q15, Q16, Q19, Q20) and a 7-item T-AI (Q21, Q23, Q26, Q27, Q30, Q33, Q36). The structural equation model is shown in Fig. 2.

The Cronbach $\alpha$ of S-AI and T-AI are 0.924 and 0.936 . The $r^{2}$ of S-AI and T-AI are 0.781 and 0.822 . The sensitivity, specificity and Youden index of S-AI are $0.867,0.927$ and 0.794 , and those of T-AI are 0.813 , 0.912 and 0.725 .

The norm of the revised STAI is shown in Table 2. The positive rates of perioperative anxiety in different age and gender groups are shown in Tables 3 and 4.

Table 2 The Norm of Revised STAI

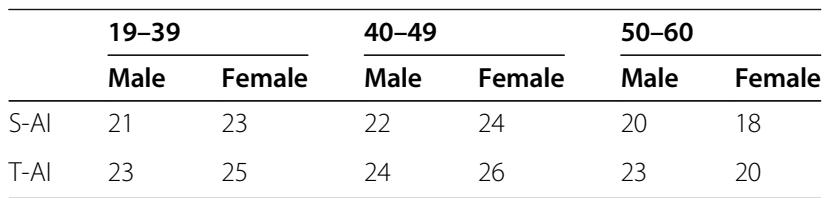

STAl State-Trait Anxiety Inventory, S-Al State Anxiety Inventory, T-Al Trait Anxiety Inventory

\section{Discussion}

The primary objective of the study was to develop a concise version of STAI which would be suitable for the assessment of perioperative anxiety in pulmonary surgery patients. Overall, the revised 13-item STAI has a good internal consistency and its structure is substantially consistent with the original STAI FormY. In addition, the application of the revised STAI will have some advantages over the original version.

Firstly, the original 40-item STAI was reported as being too long by some of the participants. And there were also some participants making answers indiscriminately, which made his reply invalid. We found that the time taken for a reply was extremely different, ranging from $1 \mathrm{~min} 40 \mathrm{~s}$ to $58 \mathrm{~min} 18 \mathrm{~s}$, with a median of $6 \mathrm{~min} 40 \mathrm{~s}$, and quartiles of $4 \mathrm{~min} 54 \mathrm{~s}$ and $9 \mathrm{~min} 41 \mathrm{~s}$. One possible reason is that an inventory with too many items will consume too much time

Table 3 The Positive Rates (\%) of Perioperative Anxiety

\begin{tabular}{|c|c|c|c|c|c|c|}
\hline & \multicolumn{2}{|l|}{$19-39$} & \multicolumn{2}{|c|}{$40-49$} & \multicolumn{2}{|l|}{$50-60$} \\
\hline & Male & $\overline{\text { Female }}$ & Male & $\overline{\text { Female }}$ & Male & Female \\
\hline S-AI & 9.1 & 20.3 & 10.3 & 6.4 & 11.7 & 45.1 \\
\hline T-Al & 27.3 & 13.3 & 17.2 & 6.4 & 10.4 & 49.3 \\
\hline STAI & 27.3 & 33.3 & 17.2 & 10.6 & 15.6 & 57.7 \\
\hline
\end{tabular}

STAl State-Trait Anxiety Inventory, S-Al State Anxiety Inventory, T-Al Trait Anxiety Inventory 
Table 4 The items retained in 13-item version of STAI

\begin{tabular}{|c|c|c|c|c|c|}
\hline & $\begin{array}{l}\text { some of the statements that people } \\
\text { indicate your most appropriate fee } \\
\text { out any statement, but the answer }\end{array}$ & $\begin{array}{l}\text { e to descr } \\
\text { he momer } \\
\text { e your mc }\end{array}$ & $\begin{array}{l}\text { nselves. Reac } \\
\text { is no right } \\
\text { opriate feelir }\end{array}$ & $\begin{array}{l}\text { tatement and t } \\
\text { g answer. Don't }\end{array}$ & $\begin{array}{l}\text { ppropriate circ } \\
\text { too much time }\end{array}$ \\
\hline & Here's how you feel at the moment. & Not at all & Somewhat & Moderately so & Very much so \\
\hline 05 & I feel at ease* & (1) & (2) & (3) & (4) \\
\hline 10 & I feel comfortable* & (1) & (2) & (3) & (4) \\
\hline 15 & I am relaxed* & (1) & (2) & (3) & (4) \\
\hline 16 & I feel content* & (1) & (2) & (3) & (4) \\
\hline 19 & I feel steady* & (1) & (2) & (3) & (4) \\
\hline 20 & I feel pleasant* & (1) & (2) & (3) & (4) \\
\hline & Here's how you feel often. & Not at all & Somewhat & Moderately so & Very much so \\
\hline 21 & I feel pleasant* & (1) & (2) & (3) & (4) \\
\hline 23 & I feel satisfied with myself* & (1) & (2) & (3) & (4) \\
\hline 26 & I feel rested* & (1) & (2) & (3) & (4) \\
\hline 27 & I am 'calm, cool and collected'* & (1) & (2) & (3) & (4) \\
\hline 30 & I am happy* & (1) & (2) & (3) & (4) \\
\hline 33 & I feel secure* & (1) & (2) & (3) & (4) \\
\hline 36 & I am content* & (1) & (2) & (3) & (4) \\
\hline
\end{tabular}

Reverse counting items are shown with *

and effort of the participant. It would affect the compliance of some of the participants, especially those not very concerned about the study. The response rate would also be affected by the number of items.

Secondly, the response requires a period of time. While the patients need much time for preoperative accessory examination, preoperative communication and signature, preoperative preparation, and so on. A concise inventory would make it easier for the participants schedule the time without interfering with other arrangements.

Finally, the revised STAI still contains the two subscales of S-AI and T-AI, with good reliability and validity. It will not affect the follow-up study to distinguish the clinical characteristics of patients with different levels and types of anxiety.

The study also has some limitations that should be acknowledged. Firstly, this study is a singlecenter study. While, our department ranked 1st in Zhejiang Province and 10th in mainland China in 2017, and our hospital ranked 1st in Zhejiang Province and 10th in mainland China in 2018. It should be said that the participants in this study are wellrepresented in East China. However, it cannot be ruled out that the participants in this study may have different clinical and psychological characteristics from the ones in other regions of the country, due to the regional, economic and other reasons. But as a pilot study, the results are still sufficient for the follow-up study.
In addition, the clinical and social characteristics of the participants, including the lesion size, the resection range, preoperative diagnosis, patients' awareness of the condition, history of surgery with general anesthesia, education level, family structure, family income, etc., were not distinguished in this study. These contents need further research.

Patients in different age and gender groups have different positive rates of perioperative anxiety. According to the result, the follow-up study will be conducted on female patients between 50 and 60 years old. And we will try to draw a norm of perioperative anxiety for female patients over 61 years old.

\section{Conclusions}

In this study, a revised STAI was developed to assess perioperative anxiety in pulmonary surgery patients. The inventory has good reliability and validity, and is suitable for follow-up study. Lung cancer has a high incidence and mortality. It is a very meaningful work to carry out a study on the assessment and intervention of perioperative anxiety of pulmonary surgery patients.

\section{Abbreviations}

STAl: State-Trait Anxiety Inventory; ERAS: Enhanced recovery after surgery; CV: Coefficient of variation; CC: Correlation coefficient; PCA: Principal component analysis; SEM: Structural equation model; GFI: Goodness-of-Fit Index; RMSEA: Root Mean Square Error of Approximation; S-Al: State subscale of STAl; T-Al: Trait subscale of STAI 


\section{Appendix}

Table 5 State-Trait Anxiety Inventory

\begin{tabular}{|c|c|c|c|c|c|}
\hline & Here's how you feel at the moment. & Not at all & Somewhat & Moderately so & Very much so \\
\hline 01 & I feel calm* & (1) & (2) & (3) & (4) \\
\hline 02 & I feel secure* & (1) & (2) & (3) & (4) \\
\hline 03 & I am tense & (1) & (2) & (3) & (4) \\
\hline 04 & I feel strained & (1) & (2) & (3) & (4) \\
\hline 05 & I feel at ease ${ }^{*}$ & (1) & (2) & (3) & (4) \\
\hline 06 & I feel upset & (1) & (2) & (3) & (4) \\
\hline 07 & I am presently worrying over possible misfortunes & (1) & (2) & (3) & (4) \\
\hline 08 & I feel satisfied* & (1) & (2) & (3) & (4) \\
\hline 09 & I feel frightened & (1) & (2) & (3) & (4) \\
\hline 10 & I feel comfortable* & (1) & (2) & (3) & (4) \\
\hline 11 & I feel self-confident ${ }^{*}$ & (1) & (2) & (3) & (4) \\
\hline 12 & I feel nervous & (1) & (2) & (3) & (4) \\
\hline 13 & I am jittery & (1) & (2) & (3) & (4) \\
\hline 14 & I feel indecisive & (1) & (2) & (3) & (4) \\
\hline 15 & I am relaxed* & (1) & (2) & (3) & (4) \\
\hline 16 & I feel content* & (1) & (2) & (3) & (4) \\
\hline 17 & I am worried & (1) & (2) & (3) & (4) \\
\hline 18 & I feel confused & (1) & (2) & (3) & (4) \\
\hline 19 & I feel steady* & (1) & (2) & (3) & (4) \\
\hline \multirow[t]{2}{*}{20} & I feel pleasant* & (1) & (2) & (3) & (4) \\
\hline & Here's how you feel often. & Not at all & Somewhat & Moderately so & Very much so \\
\hline 21 & I feel pleasant* & (1) & (2) & (3) & (4) \\
\hline 22 & I feel nervous and restless & (1) & (2) & (3) & (4) \\
\hline 23 & I feel satisfied with myself* & (1) & (2) & (3) & (4) \\
\hline 24 & I wish I could be as happy as other seem to be* & (1) & (2) & (3) & (4) \\
\hline 25 & I feel like a failure & (1) & (2) & (3) & (4) \\
\hline 26 & I feel rested* & (1) & (2) & (3) & (4) \\
\hline 27 & I am 'calm, cool and collected'* & (1) & (2) & (3) & (4) \\
\hline 28 & I feel that difficulties are piling up so that I cannot overcome them & (1) & (2) & (3) & (4) \\
\hline 29 & I worry too much over something that really doesn't matter & (1) & (2) & (3) & (4) \\
\hline 30 & I am happy* & (1) & (2) & (3) & (4) \\
\hline 31 & I have disturbing thoughts & (1) & (2) & (3) & (4) \\
\hline 32 & I lack self-confidence & (1) & (2) & (3) & (4) \\
\hline 33 & I feel secure* & (1) & (2) & (3) & (4) \\
\hline 34 & I make decision easily* & (1) & (2) & (3) & (4) \\
\hline 35 & I feel inadequate & (1) & (2) & (3) & (4) \\
\hline 36 & I am content* & (1) & (2) & (3) & (4) \\
\hline 37 & Some unimportant thought runs through my mind and bothers me & (1) & (2) & (3) & (4) \\
\hline 38 & I take disappointments so keenly that I can't put them out of my mind & (1) & (2) & (3) & (4) \\
\hline 39 & I am steady person* & (1) & (2) & (3) & (4) \\
\hline 40 & I get in a state of tension or turmoil as I think over my recent concerns and interests & (1) & (2) & (3) & (4) \\
\hline
\end{tabular}

Reverse counting items are shown with * 


\section{Acknowledgements}

None.

\section{Authors' contributions}

Zhenyu Zhou, Manli Huang and Jian Hu contributed to the design of the work. Zhenyu Zhou, Ying Wang, Zhehao He and Yuqiong Zhou contributed to the measurement of the inventory. Yuequn Niu and Wang Lv contributed to the data analysis. Zhenyu Zhou, Wang Lv and Jian Hu contributed to the manuscript. All authors have approved the final draft of the manuscript.

\section{Funding}

This study was funded by General Program of Zhejiang Provincial Natural Science Foundation (Joint Fund of Zhejiang Society of Mathematical Medicine) (LSY19H180013), National Key Research and Development Project (2017YFC0113500), Major Science and Technology Projects of Zhejiang Province (2014C03032), Research Center for Lung Tumor Diagnosis and Treatment of Zhejiang Province (JBZX-202007), Key disciplines of traditional Chinese medicine (integration of Chinese and Western Medicine) of Zhejiang Province (2017-XK-A33), The First Session of Educational Reform Research Projects in 13th Five-year Plan of Higher Education of Zhejiang University (Zdjg08078), General Research Program in Medicine and Health of Zhejiang Province (2018KY400, 2019328069), The Clinical Research Fund Project of Zhejiang Medical Association (2018YC-A17), The Fund for Scientific Research of Traditional Chinese Medicine of Zhejiang Province (2017ZA084, 2016ZA125), Teaching Reform Project of School of Medicine, Zhejiang University (jgyb20202008), Teaching Reform Project of the First Affiliated Hospital, School of Medicine, Zhejiang University (zyjg202006).

\section{Availability of data and materials}

The datasets used during the current study are available from the corresponding author on reasonable request.

\section{Ethics approval and consent to participate}

The study protocol was approved by the Institutional Review Board of the First Affiliated Hospital, School of Medicine, Zhejiang University.

The patients were verbally informed that their feedback would be included in some study. And before the body of the scale, there's also an informed consent page, stressing once again that the completion of the survey was voluntary, their responses would be anonymous, and that there would be no negative consequences from opting not to participate in the study. Once approved, the scale would jump to the body. This method for consent was practical.

\section{Consent for publication}

Not applicable.

\section{Competing interests}

The authors declare that they have no competing interests.

\section{Author details}

'Department of Thoracic Surgery, the First Affiliated Hospital, School of Medicine, Zhejiang University, Hangzhou 310003, China. ${ }^{2}$ Operation Room, the First Affiliated Hospital, School of Medicine, Zhejiang University, Hangzhou 310003, China. ${ }^{3}$ Department of Psychiatry, the First Affiliated Hospital, School of Medicine, Zhejiang University, Hangzhou 310003, China.

Received: 21 March 2020 Accepted: 22 September 2020

Published online: 28 October 2020

\section{References}

1. Siegel RL, Miller KD, Jemal A. Cancer statistics, 2019. CA Cancer J Clin. 2019; 69(1):7-34.

2. Rao S, Ye L, Min L, Zhao G, Chen Y, Huang Y, et al. Meta-analysis of segmentectomy versus lobectomy for radiologically pure solid or solid-dominant stage IA non-small cell lung cancer. J Cardiothorac Surg. 2019;14(1):197.

3. Woodard GA, Jones KD, Jablons DM. Lung Cancer staging and prognosis. Cancer Treat Res. 2016;170:47-75.

4. Detterbeck FC, Boffa DJ, Kim AW, Tanoue LT. The eighth edition lung Cancer stage classification. Chest. 2017;151(1):193-203.
5. Avery KNL, Blazeby JM, Chalmers KA, Batchelor TJP, Casali G, Internullo E, et al. Impact on health-related quality of life of video-assisted thoracoscopic surgery for lung cancer. Ann Surg Oncol. 2019;27(4):1259-71.

6. Fang $L, X u$ J, Ye $B, Y u$ G, Chen $G$, Yang J. Is lobe specific lymph node dissection adequate for cNO-1 non-small cell lung cancer? J Cardiothorac Surg. 2020;15(1):46.

7. Joshi GP, Kehlet H. Postoperative pain management in the era of ERAS: an overview. Best Pract Res Clin Anaesthesiol. 2019;33(3):259-67.

8. Chiappetta M, laffaldano A, Ciavarella LP, Meacci E, Margaritora S. Chest ultrasound: enhanced recovery after surgery (ERAS) best friend in general thoracic surgery. J Thorac Dis. 2019;11(S15):S2026-7.

9. Ljungqvist $\mathrm{O}$. ERAS--enhanced recovery after surgery: moving evidence-based perioperative care to practice. J Parenter Enter Nutr. 2014;38(5):559-66.

10. Shen C, Che G. Tubeless minimally invasive treatment: taking a new step in enhanced recovery after surgery (ERAS). Thorac Cancer. 2019;10(11):2067-70.

11. Huang JS, Xu N, Sun KP, Hong ZN, Chen LW, Kuo YR, et al. Comparison of quality of life in patients who underwent mechanical mitral valve replacement: star GK vs SJM. J Cardiothorac Surg. 2020;15(1):2.

12. Bailey L. Strategies for decreasing patient anxiety in the perioperative setting. AORN J. 2010;92(4):445-60.

13. Vagnoli L, Bettini A, Amore E, De Masi S, Messeri A. Relaxation-guided imagery reduces perioperative anxiety and pain in children: a randomized study. Eur J Pediatr. 2019;178(6):913-21.

14. Yung PM, Fung MY, Chan TM, Lau BW. Relaxation training methods for nurse managers in Hong Kong: a controlled study. Int J Ment Health Nurs. 2004;13(4):255-61.

15. Verschueren $S$, van Aalst J, Bangels A, Toelen J, Allegaert K, Buffel $C$, et al. Development of CliniPup, a serious game aimed at reducing perioperative anxiety and pain in children: mixed methods study. JMIR Serious Games. 2019;7(2):e12429.

16. Williams H, Jajja MR, Baer W, Balch GC, Maithel SK, Patel AD, et al. Perioperative anxiety and depression in patients undergoing abdominal surgery for benign or malignant disease. J Surg Oncol. 2019;120(3):389-96

17. Park ES, Yim HW, Lee KS. Progressive muscle relaxation therapy to relieve dental anxiety: a randomized controlled trial. Eur J Oral Sci. 2019;127(1):45-51.

18. Sridhar S, Suprabha BS, Shenoy R, Shwetha KT, Rao A. Effect of a relaxation training exercise on behaviour, anxiety, and pain during buccal infiltration anaesthesia in children: randomized clinical trial. Int J Paediatr Dent. 2019. 29(5):596-602.

19. Chen YF, Huang XY, Chien $\mathrm{CH}$, Cheng JF. The effectiveness of diaphragmatic breathing relaxation training for reducing anxiety. Perspect Psychiatr Care. 2017;53(4):329-36.

20. Bergua V, Meillon C, Potvin O, Ritchie K, Tzourio C, Bouisson J, et al. Short STAI-Y anxiety scales: validation and normative data for elderly subjects. Aging Ment Health. 2016:20(9):987-95.

21. Grupe DW, Nitschke JB. Uncertainty and anticipation in anxiety: an integrated neurobiological and psychological perspective. Nat Rev Neurosci. 2013;14(7):488-501.

22. Perez E, Dzierzewski JM, Aiken-Morgan AT, McCrae CS, Buman MP, Giacobbi $P R$, et al. Anxiety and executive functions in mid-to-late life: the moderating role of sleep. Aging Ment Health. 2020;24(9):1459-65.

23. Al-Yateem $\mathrm{N}$, Brenner M. Validation of the short state trait anxiety inventory (short STAI) completed by parents to explore anxiety levels in children. Comprehensive Child Adolesc Nurs. 2017:40(1):29-38

24. Ruiz-Fernandez MD, Ortiz-Amo R, Ortega-Galan AM, Ibanez-Masero O, Rodriguez-Salvador M, Ramos-Pichardo JD. Mindfulness therapies on health professionals. Int J Ment Health Nurs. 2020;29(2):127-40.

25. Lobbes H, Dehos J, Pereira B, Le Guenno G, Sarry L, Ruivard M. Computed and subjective blue scleral color analysis as a diagnostic tool for iron deficiency: a pilot study. J Clin Med. 2019;8(11):1876.

\section{Publisher's Note}

Springer Nature remains neutral with regard to jurisdictional claims in published maps and institutional affiliations. 